\title{
Factors Related to Adolescent Smoking: A Nationally Representative Cross-Sectional Study in Thailand
}

\author{
Charin Suwanwong $^{1 *} \mathbb{D}$, Romtawan Kalapat ${ }^{2,3} \mathbb{D}$, Siriwan Pitayarangsarit ${ }^{4} \mathbb{D}$, Surasak Chaiyasong ${ }^{5} \mathbb{D}$ \\ ${ }^{1}$ Independent Researcher, Bangkok, Thailand; ${ }^{2}$ International Health Policy Program (IHPP), Ministry of Public Health, Thailand; \\ ${ }^{3}$ Social Pharmacy Research Unit, Mahasarakham University, Mahasarakham, Thailand; ${ }^{4}$ Bureau of Non Communicable \\ Disease, Ministry of Public Health, Nonthaburi, Thailand; ${ }^{5}$ Department of Social and Administrative Pharmacy, Faculty of \\ Pharmacy, Mahasarakham University, Mahasarakham, Thailand
}

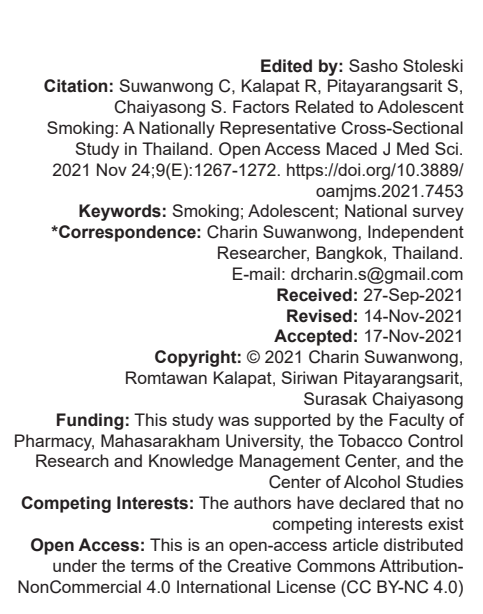

\section{Abstract}

AIM: This study aimed to explore the individual, familial, and social factors associated with different smoking statuses in Thai adolescents.

METHODS: The nationally representative sample of 6046 adolescents aged 15-19 years took part in the 2017 Cigarette Smoking and Alcohol Drinking Behavior Survey in Thailand. Multinomial logistic regression analysis was conducted to explore the associations between the individual, familial, and social factors and different smoking statuses.

RESULTS: The daily smoking and occasional smoking was $6.4 \%$ and $3.3 \%$, respectively. Gender, alcohol use substance use, attitudes toward smoking, exposure to secondhand smoke (SHS) at home, anti-smoking social media campaign, and graphic warning labels were related to daily and occasional smoking. Daily smoking was associated with exposure to SHS at school, restaurants, public transport, and exposure to tobacco advertising.

CONCLUSION: These findings suggest that smoking prevention intervention should focus on these factors and develop anti-smoking policies for smoking prevention among adolescents.

\section{Introduction}

According to 2017 Thailand tobacco consumption statistics reported by the Tobacco Control Research and Knowledge Management Center [1], the number of Thai smokers aged more than 15 years was 10.7 million (19.1\%), and the tobacco use rate in adolescents aged $15-18$ years was $7.8 \%$. Overall, the daily smoking rate had declined from $95 \%$ in 1991 to $88 \%$ in 2017 , but the number of occasional smokers has gradually increased from 590,528 in 1991 to 1,251,695 in 2017. Recent data suggest that this increase could signify that the tobacco industry has a new marketing strategy that might affect increasing adolescent tobacco experimenters.

For adolescents, various tobacco control plans have been implemented [2], such as (1) teen smoking prevention: To reduce the initiations of adolescents to smoking, secondary schools, participate in smokefree school projects, and (2) help teen quitting: To encourage quitting smoking or decrease the uptake of smoking. These plans can help in reducing teen smoking initiation or reducing smoking uptake. Still, these plans can be limited in effectiveness because of tobacco companies using social media as channels for the marketing and promotion of tobacco products. There is strong evidence that adolescents are vulnerable to influence by the tobacco industry [3]. Approximately, $90 \%$ of the people who smoke for the first time begin during adolescence [4]. Most adults who habitually smoke began to smoke as adolescents [5], so it is crucial to monitor and prevent adolescent smoking. In this research, we used the socioecological model [6] to explain adolescent smoking. This model provides a framework to examine the relationships between individuals and their environments, divided into three levels: Individual, interpersonal and environmental factors. We expect that the individual, familial, and social factors should encourage adolescents not to begin smoking. However, there have not been any studies focusing on the factors related to adolescent smoking using the national cohort database in Thailand. Thus, this study aimed to explore the individual, familial, and social factors related to adolescent smoking in Thailand. It was hoped that this study would provide information for policymakers to help them create and 
implement policies focused on preventing and reducing adolescent smoking nationwide.

\section{Methods}

This study was based on secondary data from the 2017 Cigarette Smoking and Alcohol Drinking Behavior Survey (CSAD) conducted in Thailand's National Statistical Office every three years. This CSAD was undertaken to obtain information on smoking status, sociodemographic, and smoking-related variables. Of the 15499 total respondents to CSAD 2017 aged between 15 and 19-years-old. Among 9453 respondents were excluded from the analyses because of missing relevant data. The final sample included a total of 6046 respondents aged 15-19. This study received Institutional Review Board Approval (No. 018/2019).

\section{Study variables}

Demographic variables included gender, alcohol use, and substance use. Self-reported smoking status was assessed with the following question: Do you smoke at present? The answer categories were "never," "ever," "yes, occasionally," and "yes, daily." The main outcomes were grouped into "never-smokers," "occasionally Smokers," and "daily Smokers."

\section{Individual factors}

Individual factors consisted of knowledge of smoking-related disease and attitudes toward smoking. Knowledge of smoking-related diseases was assessed with 12 questions: Which diseases are caused from smoking harm? (e.g., lung cancer, hypertension, etc.). Knowledge was dichotomized as 0 (low) and 1 (high). The question measured attitudes toward smoking: Do you agree that smoking should be categorized as hazardous to health. These responses were divided into two categories: Negative (agree) and positive (disagree).

\section{Familial factors}

Exposure to secondhand smoke (SHS) at home was assessed by the question: How often did a family member smoke at your home. This item was scored on a 6-point rating scale (ranged between 0 and 5). Respondents who answer 1-5 points were classified as exposed to SHS at home.

\section{Social factors}

Social factors consisted of exposure to SHS at school, restaurant, and public transport, Exposure to tobacco marketing and advertising, anti-smoking social media campaign, and graphic warning label. Exposure to SHS at school, restaurant, and public transport was identified by the question: Have you ever seen someone smoke in the public. Exposure to tobacco marketing was measured by the question: Within the past 30 days, have you seen smoking promotional strategies. exposure tobacco advertising was assessed by the question: Within the past 30 days, have you seen smoking advertisements. Respondents who answered "yes" were classified as exposure. Antismoking social media campaign was assessed by the question: Within the past 30 days, have you seen any information about anti-smoking in social media. Graphic warning labels was measured by the question: Within the past 30 days, have you noticed the warning label on smoking products. Respondents who answer "yes" were classified as perceived smoking-related harm.

\section{Statistical analysis}

The data were coded and analyzed using SPSS version 26 (IBM Corp., Armonk, NY, USA). At first, the association of different adolescent smoking status was tested with individual, familial, and social factors using the Chi-square test for group differences. Multinomial logistic regression analysis was used to examine the association between the factors and adolescent smoking status. The dependent variable was adolescent smoking status, with never-smokers as the reference category. We calculated the odds ratios (OR) with 95\% confidence intervals (Cls) for each variable, and $p<$ 0.05 was considered to be statistically significant.

\section{Results}

Table 1 presents the demographic characteristics. Of the 6046 adolescents included in the study, $50.1 \%$ were male, and $49.9 \%$ were female. The prevalence of alcohol use and substance use was $14.7 \%$ and $2.0 \%$, respectively. The prevalence of daily smoking and occasional smoking was $6.4 \%$ and $3.3 \%$, respectively.

Table 1: Demographic characteristics of adolescents $(n=6046)$

\begin{tabular}{lll}
\hline Characteristics & Classification & $\mathrm{n}(\%)$ \\
\hline Gender & Male & $3032(50.1)$ \\
& Female & $3014(49.9)$ \\
Alcohol Use & No & $5156(85.3)$ \\
\multirow{2}{*}{ Substance Use } & Yes & $890(14.7)$ \\
& No & $5927(98.0)$ \\
Smoking Status & Yes & $119(2.0)$ \\
& Never-smoker & $5467(90.3)$ \\
& Occasional smoker & $202(3.3)$ \\
& Daily smoker & $384(6.4)$ \\
\hline
\end{tabular}

Chi-square test revealed significant differences between adolescent smoking and individual factors 
(knowledge of smoking-related disease, attitudes toward smoking), familial factor (Exposure to SHS at home), and social factors (Exposure to SHS at school, restaurant, and public transport, exposure to tobacco advertising, anti-smoking social media campaign, graphic warning labels) (Table 2).

Table 2: Smoking prevalence of adolescents

\begin{tabular}{|c|c|c|c|c|}
\hline Factors & Never-Smoker & $\begin{array}{l}\text { Occasional } \\
\text { Smoker }\end{array}$ & $\begin{array}{l}\text { Daily } \\
\text { Smoker }\end{array}$ & $\chi^{2}$ \\
\hline Knowledge of smoking-related disease & 70.5 & 65.8 & 58.3 & $26.624^{\star \star *}$ \\
\hline Attitudes toward smoking & 96.0 & 84.2 & 72.6 & $394.987^{* * *}$ \\
\hline Exposure to SHS at home & 28.3 & 59.4 & 72.1 & $387.594^{\star \star *}$ \\
\hline Exposure to SHS at school & 17.5 & 13.3 & 23.8 & $10.233^{\star *}$ \\
\hline Exposure to SHS at restaurant & 39.0 & 39.6 & 46.9 & $9.417^{\star *}$ \\
\hline Exposure to SHS at public transport & 30.2 & 25.2 & 25.0 & $6.637^{\star}$ \\
\hline Exposure to tobacco marketing & 3.6 & 5.9 & 7.0 & 5.301 \\
\hline Exposure to tobacco advertising & 11.3 & 13.9 & 19.0 & $21.166^{\star *}$ \\
\hline Anti-smoking social media campaign & 36.3 & 24.3 & 22.9 & $39.122^{* \star *}$ \\
\hline Graphic warning labels & 64.1 & 78.2 & 72.6 & $27.346^{\text {***}}$ \\
\hline
\end{tabular}

${ }^{\star} p<0.05,{ }^{* *} p<0.01,{ }^{* \star *} p<0.001$. SHS: Secondhand smoke.

The results of multinomial logistic regression analysis (Table 3 ) revealed that the higher risks for being adolescent daily smokers were exposed to SHS at home (OR, 6.63; 95\% Cl, 4.98-8.82), school (OR, 2.02; 95\% Cl, 1.38-2.97), restaurant (OR, 1.57; 95\% $\mathrm{Cl}, 1.17$ to 2.10 ), and public transport (OR, 1.42; 95\% $\mathrm{Cl}, 1.02-1.98$ ), and tobacco advertising (OR, 1.90; $95 \% \mathrm{Cl}, 1.31-2.75)$. Meanwhile, those who perceived negative attitudes toward smoking (OR, 0.18; $95 \% \mathrm{Cl}$, 0.12-0.26), had seen the information of anti-smoking on social media (OR, 0.59; 95\% Cl, 0.43-0.81), and also noticed graphic warning labels (OR, 0.67; 95\% Cl, 0.49-0.92) had a lower risk of adolescent daily smoking. However, results found that adolescent daily smoking was not significantly associated with knowledge of smoking-related disease.

Table 3: Multinomial logistic regression analysis for adolescent smoking

\begin{tabular}{|c|c|c|c|}
\hline Variables & Classification & Occasional Smoker & Daily Smoker \\
\hline \multirow[t]{2}{*}{ Gender } & Female & 1.00 (reference) & 1.00 (reference) \\
\hline & Male & $12.95(6.92,24.23)^{\star * \star}$ & $34.29(16.62,70.73)^{* * *}$ \\
\hline \multirow[t]{2}{*}{ Alcohol use } & No & 1.00 (reference) & 1.00 (reference) \\
\hline & Yes & $15.23(10.95,21.19)^{\star \star \star}$ & $17.05(12.87,22.59)^{\star \star \star}$ \\
\hline \multirow[t]{2}{*}{ Substance use } & No & 1.00 (reference) & 1.00 (reference) \\
\hline & Yes & $4.46(2.16,9.24)^{\star \star \star}$ & $4.80(2.54,9.07)^{\star \star \star}$ \\
\hline \multirow{2}{*}{$\begin{array}{l}\text { Knowledge of } \\
\text { smoking-related } \\
\text { disease }\end{array}$} & Low & 1.00 (reference) & 1.00 (reference) \\
\hline & High & $1.00(0.71,1.41)$ & $1.23(0.92,1.63)$ \\
\hline \multirow{2}{*}{$\begin{array}{l}\text { Attitudes toward } \\
\text { smoking }\end{array}$} & Positive & 1.00 (reference) & 1.00 (reference) \\
\hline & Negative & $0.34(0.22,0.55)^{\star \star \star}$ & $0.18(0.12,0.26)^{\star \star \star}$ \\
\hline \multirow{2}{*}{$\begin{array}{l}\text { Exposure to SHS at } \\
\text { home }\end{array}$} & No & 1.00 (reference) & 1.00 (reference) \\
\hline & Yes & $3.47(2.52,4.79)^{\star \star \star}$ & $6.63(4.98,8.82)^{* \star *}$ \\
\hline \multirow{2}{*}{$\begin{array}{l}\text { Exposure to SHS at } \\
\text { school }\end{array}$} & No & 1.00 (reference) & 1.00 (reference) \\
\hline & Yes & $0.89(0.60,1.32)$ & $2.02(1.38,2.97)^{\star \star \star}$ \\
\hline \multirow{2}{*}{$\begin{array}{l}\text { Exposure to SHS at } \\
\text { restaurant }\end{array}$} & No & 1.00 (reference) & 1.00 (reference) \\
\hline & Yes & $1.04(0.73,1.48)$ & $1.57(1.17,2.10)^{\star \star}$ \\
\hline \multirow{4}{*}{$\begin{array}{l}\text { Exposure to SHS at } \\
\text { public transport } \\
\text { Exposure to tobacco } \\
\text { advertising }\end{array}$} & No & 1.00 (reference) & 1.00 (reference) \\
\hline & Yes & $1.29(0.88,1.91)$ & $1.42(1.02,1.98)^{*}$ \\
\hline & No & 1.00 (reference) & 1.00 (reference) \\
\hline & Yes & $1.29(0.81,2.04)$ & $1.90(1.31,2.75)^{\star \star}$ \\
\hline \multirow{4}{*}{$\begin{array}{l}\text { Anti-smoking social } \\
\text { media campaign } \\
\text { Graphic warning labels }\end{array}$} & No & 1.00 (reference) & 1.00 (reference) \\
\hline & Yes & $0.53(0.36,0.77)^{\star \star}$ & $0.59(0.43,0.81)^{\star \star}$ \\
\hline & No & 1.00 (reference) & 1.00 (reference) \\
\hline & Yes & $0.51(0.35,0.74)^{\star \star}$ & $0.67(0.49,0.92)^{*}$ \\
\hline
\end{tabular}

The results also revealed that the higher risks for being adolescent occasional smokers were exposed to SHS at home (OR, 3.47; 95\% Cl, 2.52-4.79). Meanwhile, those who perceived negative attitudes toward smoking (OR, 0.34; 95\% Cl, 0.22-0.55), had seen the information of anti-smoking on social media
(OR, 0.53; 95\% Cl, 0.36-0.77), and also noticed graphic warning labels $(\mathrm{OR}, 0.51 ; 95 \% \mathrm{Cl}, 0.35-0.74)$ had a lower risk of adolescent occasional smoking.

However, results found that both daily and occasional smoking was not significantly associated with knowledge of smoking-related disease. No significant associations were found between occasional smoking and exposure to SHS at school, restaurant and public transport, as well as tobacco advertising.

In addition, the results found that those with alcohol use had a 15-17 times higher likelihood of both being the daily smokers (OR, 17.05; 95\% Cl, 12.8722.59) and occasional smokers (OR, 15.23; $95 \% \mathrm{Cl}$, 10.95-21.19) than the never smokers. Substance use was associated with a 4-5 times higher likelihood of both being the daily smokers (OR, 4.80; 95\% Cl, 2.54-9.07) and occasional smokers (OR, 4.46; $95 \% \mathrm{Cl}$, 2.16-9.24) than the never smokers.

\section{Discussion}

This study examined the association of individual, familial, and social factors with smoking status in the Thai adolescent population. The prevalence of daily and occasional smoking among adolescents was $6.4 \%$ and $3.3 \%$, respectively. Male were more likely to smoke than female. This result is consistent with previous studies in Thailand [7], [8]. In Thai society, males' smoking is more considered as socially acceptable than smoking by females [9]. Accordingly, smoking by male is a serious health problem in Thailand. Alcohol use and substance use were associated with adolescent smoking. These results indicated that cigarettes, alcohol, and other substances tend to be used together [10]. Consistent with previous studies, alcohol use and substance use were associated with an increase in the likelihood of smoking among adolescents [10], [11], [12].

Individual factor such as attitudes toward smoking was negative associated with adolescent smoking. Attitude toward smoking play a protective role against adolescent smoking [13]. Adolescent with negative attitudes toward smoking are less likely to smoke than those with positive attitudes toward smoking. These results are in line with other studies [13], [14], [15]. Encouraging negative attitudes toward smoking might prevent smoking initiation and also encourage smoking cessation among adolescents.

Our results suggest that exposure to SHS at home increased the risk for adolescent smoking in both daily and occasional smokers. This finding is consistent with previous studies, which reported that adolescents who were current smokers had a higher likelihood of being exposed to SHS at home [16], [17], [18]. A previous 
study [19] showed that exposure to SHS at home predicted adolescent smoking initiation. In addition, youth with high parental monitoring/supervision or home smoking bans appeared to decrease the likelihood of adolescent smoking [20], [21], [22]. Our study points out the importance of the familial factor and should be considered due to the highest risk factors. Hence, the government should enact a law prohibiting smoking. Prevention programs and implemented policies should continue promoting smoke-free homes. Parents should quit smoking inside their homes, leading adolescents not to try smoking, or reduce smoking initiation.

Social factors such as exposure to SHS in public places (school, restaurant, and public transport) and exposure to tobacco advertising were positively associated with adolescent daily smoking. Exposure to SHS in public places was higher among daily smokers, consistent with other studies [23], [24]. SHS exposure in a public place might be a risk factor among adolescent smoking [17]. This is probably because of the poor strict implementation of the smoke-free law. Therefore, comprehensive smoke-free law in public places and intervention to reduce SHS exposure is needed. The present study revealed that adolescents exposed to tobacco advertising appeared to increase the odds of smoking. Other previous studies found an association between tobacco advertising and adolescent daily smokers [25], [26], [27]. There is a comprehensive ban and restriction on tobacco advertising [28], but adolescents still have been exposed to tobacco advertising. Tobacco control efforts should focus on strict enforcement of existing tobacco control laws.

In addition, social factors such as anti-smoking social media campaigns and perceived graphic warning labels decreased the risk for adolescent smoking in both daily and occasional smokers. Adolescents who were exposed to related anti-smoking messages on social media were less likely to smoke. A possible explanation for this finding is that social media messages may serve as effective strategies for adolescents. Previous studies showed the benefit of social media in promoting anti-smoking messages to reduce and quit smoking [29], [30], [31]. Thus, social media-based intervention about anti-smoking messages is further needed. The present study also revealed that adolescents who were perceived graphic warning labels appeared to decrease the likelihood of smoking. Recently, Drovandi et al. [32] reported that graphic warning labels strongly affected adolescent never-smokers. Graphic warning labels may help to reduce smoking [33] and decide not to start smoking among adolescents [34], [35]. This is probably because these warnings may increase health awareness. Developing effective graphic warning labels is needed to prevent smoking onset among adolescents.

This limitation of the study was its crosssectional design. Cross-sectional design cannot be used to infer causality or cause and effect. This is the reason why further research will be needed. Future studies should be longitudinal studies to investigate the influence and the relationship of independent variables on smoking status with different periods. They may use qualitative data for such in-depth details. The major strength of this study is that this is the first study to investigate socioecological factors associated with adolescent smoking in Thailand on a national scale. We hope that our findings will provide better insight into the significance of socioecological factors in predicting adolescent smoking. This will allow the development of strategies to integrate smoking interventions with a socioecological approach to help adolescents avoid smoking initiation and promote smoking cessation.

\section{Conclusion}

Based on the research findings, we can conclude that the individual, familial, and social factors on adolescent smoking in Thailand. These findings suggest that smoking prevention intervention should focus on these factors and develop anti-smoking policies for smoking prevention among adolescents.

\section{Acknowledgments}

This study was done under the project of "Situation, trends and factors associated with tobacco and alcohol consumption in Thailand: Analysis of cigarette smoking and alcohol drinking behavior surveys during 1999-2017" of the Faculty of Pharmacy, Mahasarakham University, the Tobacco Control Research and Knowledge Management Center (TRC), and the Center of Alcohol Studies (CAS). We also thank the National Statistical Office for providing the CSAD data.

\section{References}

1. Tobacco Control Research and Knowledge Management Center. 2018 Tobacco Consumption Statistics Report in Thailand. Bangkok: Charoendee Munkong; 2018.

2. Department of Disease Control. Tobacco Control Plan $2017-$ 2021. Nonthaburi: Ministry of Public Health; 2017.

3. McCool J, Freeman B, Tanielu H. Perceived socia and media influences on tobacco use among Samoan youth. BMC Public Health. 2014;14:1100. https://doi. org/10.1186/1471-2458-14-1100

PMid:25342603

4. Park S. Smoking and adolescent health. Korean J Pediatr 
2011;54(10):401-4. https://doi.org/10.3345/kjp.2011.54.10.401 PMid:22232621

5. Fidler JA, Wardle J, Broderson $\mathrm{NH}$, Jarvis MJ, West $\mathrm{R}$ Vulnerability to smoking after trying a single cigarette can lie dormant for three years or more. Tob Control. 2006;15(3):205-9. https://doi.org/10.1136/tc.2005.014894

PMid: 16728751

6. Stokols D. Translating social ecological theory into guidelines for community health promotion. Am J Health Promot. 1996;10(4):282-98. https://doi.org/10.4278/0890-1171-10.4.282 PMid:10159709

7. Joung $\mathrm{KH}$, Chung SS. Factors affecting cigarette smoking among adolescents in South Korea, Vietnam, and Thailand. J Spec Pediatr Nurs. 2019;24(4):e12267. https://doi.org/10.1111/ jspn.12267

PMid:31468713

8. Chotbenjamaporn $P$, Haruhansapong $V$, Jumriangrit $P$, Pitayarangsarit S, Agarwal N, Garg R. Tobacco use among Thai students: Results from the 2015 global youth tobacco survey. Indian J Public Health 2017;61(Suppl 1):40-6. https:// doi.org/10.4103/ijph.IJPH_234_17

PMid:28928318

9. Chinwong D, Mookmanee N, Chongpornchai J, Chinwong S. A comparison of gender differences in smoking behaviors, intention to quit, and nicotine dependence among Thai university students. J Addict. 2018;2018:8081670. https://doi. org/10.1155/2018/8081670

PMid:30473903

10. Bakar C, Gündogar D, Karaman HIO, Maral I. Prevalence and related risk factors of tobacco, alcohol and illicit substance use among university students. Eur J Psychiat. 2013;27(2):97-110. https://doi.org/10.4321/S0213-61632013000200003

11. Roche DJ, Bujarski S, Green R, Hartwell EE, Leventhal AM, Ray LA. Alcohol, tobacco, and marijuana consumption is associated with increased odds of same-day substance co-and tri-use. Drug Alcohol Depend. 2019;200:40-9. https://doi. org/10.1016/j.drugalcdep.2019.02.035 PMid:31085377

12. Nowak M, Papiernik M, Mikulska A, Czarkowska-Paczek B. Smoking, alcohol consumption, and illicit substances use among adolescents in Poland. Subst Abuse Treat Prev Policy. 2018;13:42. https://doi.org/10.1186/s13011-018-0179-9

13. Albert-Lőrincz E, Paulik E, Szabo B, Foley K, Gasparik AI. Adolescent smoking and the social capital of local communities in three countries in Romania. Gac Sanit. 2019;33(6):547-53. https://doi.org/10.1016/j.gaceta.2018.05.009 PMid:30107939

14. Khubchandani J, Sharma M, Huston D, Tahiliani J. Tobacco use related attitudes and behaviors in Indian adolescents: Association with school-based prevention education. Health Promot Perspect. 2017;7(3):128-33. https://doi.org/10.15171/ hpp.2017.24 PMid:28695100

15. Garrett BE, Gardiner PS, Wright LT, Pechacek TF. The African American youth smoking experience: An overview. Nicotine Tob Res. 2016;18(Suppl 1):S11-5. https://doi.org/10.1093/ntr/ntv203 PMid:26980860

16. Ling MY, Lim KH, Hasani WS, Rifin HM, Majid NL, Lourdes TG, et al. Exposure to secondhand smoke among school-going adolescents in Malaysia: Findings from the tobacco and e-cigarettes survey among Malaysian adolescents (TECMA). Tob Induc Dis. 2020;18:96. https://doi.org/10.18332/tid/128622 PMid:33262682

17. Xi B, Liang Y, Liu Y, Yan Y, Zhao M, Ma C, et al. Tobacco use and secondhand smoke exposure in young adolescents aged
12-15 years: Data from 68 low-income and middle-income countries. Lancet Glob Health. 2016;4(11):e795-805. https://doi. org/10.1016/S2214-109X(16)30187-5

\section{PMid:27697484}

18. Al-Zalabani $\mathrm{AH}$, Amer $\mathrm{SM}$, Kasim KA, Alqabshawi RI, Abdallah AR. Secondhand smoking among intermediate and secondary school students in Madinah, Saudi Arabia. Biomed Res Int 2015;2015:672393.

19. Wang MP, Ho SY, Lam TH. Parental smoking, exposure to secondhand smoke at home, and smoking initiation among young children. Nicotine Tob Res. 2011;13(9):827-32. https:// doi.org/10.1093/ntr/ntr083

PMid:21525153

20. Wellman RJ, Dugas EN, Dutczak H, O'Loughlin EK, Datta GD Lauzon B, et al. Predictors of the onset of cigarette smoking: A systematic review of longitudinal population-based studies in youth. Am J Prev Med. 2016;51(5):767-78. https://doi. org/10.1016/j.amepre.2016.04.003

PMid:27180028

21. Mathur C, Stigler MH, Erickson DJ, Perry CL, Forster JL. Transitions in smoking behavior during emerging adulthood: A longitudinal analysis of the effect of home smoking bans. Am J Public Health. 2014;104(4):715-20. https://doi.org/10.2105/ AJPH.2013.301642

PMid:24524528

22. Lochbuehler K, Schuck K, Otten R, Ringlever L, Hiemstra M. Parental smoking and smoking cognitions among youth: A systematic review of the literature. Eur Addict Res. 2016;22:215-32. https://doi.org/10.1159/000446022

23. Ghazali SM, Huey TC, Cheong KC, Li LH, Fadhli M, Yusoff M, et al. Prevalence and factors associated with secondhand smoke exposure among Malaysian adolescents. Tob Induc Dis. 2019;17:22. https://doi.org/10.18332/tid/102728 PMid:31582933

24. Yang X, Yan Z, Xu G, Tan Y, Zhu J. How secondhand smoke exposure affects tobacco use and smoking susceptibility of adolescents: Sex and school differences. Tob Induc Dis. 2021;19:68. https://doi.org/10.18332/tid/140094 PMid:34539307

25. Hanewinkel R, Isensee B, Sargent JD, Morgenstern M. Cigarette advertising and adolescent smoking. Am J Prev Med. 2010;38(4):359-66. https://doi.org/10.1016/j. amepre.2009.12.036

PMid:20307803

26. Madkour AS, Ledford EC, Andersen L, Johnson CC. Tobacco advertising/promotions and adolescents' smoking risk in Northern Africa. Tob Control. 2014;23(3):244-52. https://doi. org/10.1136/tobaccocontrol-2012-050593 PMid:23303288

27. Prabandari YS, Dewi A. How do Indonesian youth perceive cigarette advertising? A cross-sectional study among Indonesian high school students. Glob Health Action. 2016;9:30914. https:// doi.org/10.3402/gha.v9.30914

PMid:27578600

28. Li L, Yong H, Borland R, Fong GT, Thompson ME, Jiang Y, et al. Reported awareness of tobacco advertising and promotion in China compared to Thailand, Australia and the USA. Tob Control. 2009;18(3):222-27. https://doi.org/10.1136/tc.2008.027037 PMid: 19332425

29. Hefler M, Kerrigan V, Freeman B, Boot GR, Thomas DP. Using facebook to reduce smoking among australian aboriginal and torres strait islander people: A participatory grounded action study. BMC Public Health. 2019;19:615. https://doi.org/10.1186/ s12889-019-6918-7

30. Naslund JA, Kim SJ, Aschbrenner KA, McCulloch LJ, 
Brunette MF, Dallery J, et al. Systematic review of social media interventions for smoking cessation. Addict Behav. 2017;73:81-93. https://doi.org/10.1016/j.addbeh.2017.05.002 PMid:28499259

31. Kim SJ, Marsch LA, Brunette MF, Dallery J. Harnessing Facebook for smoking reduction and cessation interventions: Facebook user engagement and social support predict smoking reduction. J Med Internet Res. 2017;19(5):e168. https://doi. org/10.2196/jmir.6681

PMid:28536096

32. Drovandi A, Teague P, Glass B, Malau-Aduli B. A systematic review of the perceptions of adolescents on graphic health warnings and plain packaging of cigarettes. Syst Rev. 2019;8(1):25. https://doi.org/10.1186/s13643-018-0933-0 PMid:30654833

33. White $\mathrm{V}$, Webster B, Wakefield M. Do graphic health warning labels have an impact on adolescents' smoking-related beliefs and behaviours? Addiction. 2008;103(9):1562-71. https://doi. org/10.1111/j.1360-0443.2008.02294.x

PMid:18783508

34. Hwang J, Cho S. The association between new graphic health warning labels on tobacco products and attitudes toward smoking among South Korean adolescents: A national crosssectional study. BMC Public Health. 2020;20(1):748. https://doi. org/10.1186/s12889-020-08638-0

PMid:32448193

35. Sirichotiratana N, Sujirarat D, Sompopcharoen M, Viwatwongkasem C, Satitvipawee P, Auemaneekul N, et al. Effectiveness of $85 \%$ graphic health warning on cigarette packs on smoking behaviours of Thai teenagers. Tob Induc Dis. 2018;16(Suppl 1):A761. https://doi.org/10.18332/tid/83827

PMid:33553059 